\title{
Diagnostic evaluation of classification criteria for rheumatoid arthritis and reactive arthritis in an early synovitis outpatient clinic
}

\author{
J L Hülsemann, H Zeidler
}

\begin{abstract}
Objective-To evaluate the diagnostic performance of classification criteria for rheumatoid arthritis (RA) and reactive arthritis $(\operatorname{Re} A)$ in an early synovitis outpatient clinic.

Methods-In a prospective two year survey consecutive patients with early synovitis of less than one year duration were documented using a standardised registry and were classified after an expert diagnosis. Of a total of 320 patients $39(19 \%)$ were diagnosed as having RA, 24 (11\%) patients had $\operatorname{ReA}, 117$ (54\%) patients did not have an unequivocal diagnosis, and were considered as undifferentiated arthritis.

Results-The retrospective application of the revised 1987 ACR criteria for the classification of RA in this data set revealed a sensitivity of $90 \%$ and a specificity of $90 \%$. The positive predictive value was 0.67 , the negative predictive value 0.98 . Similarly, the criteria for ReA of the French Society of Rheumatology (FSR) showed a sensitivity of $80 \%$ and a specificity of $90 \%$ with a positive predictive value of 0.55 and a negative predictive value of 0.97 . Both criteria sets had a satisfying likelihood ratio of 9 and 10, respectively.

Conclusion-Both the 1987 ACR criteria for RA and the criteria of the FSR for ReA have a reasonable diagnostic validity in patients with early synovitis, including a large portion of undifferentiated arthritis. (Ann Rheum Dis 1999;58:278-280)
\end{abstract}

In past decades rheumatologists have made efforts to standardise the classification and the nomenclature of rheumatic diseases. One of these efforts is the creation of classification criteria. In 1958 the American Rheumatism Association (ARA) had proposed diagnostic criteria for rheumatoid arthritis (RA). ${ }^{1}$ In 1987 the American College of Rheumatology (ACR) published a revised set of seven classification criteria. ${ }^{2}$ The term "diagnostic" criteria was replaced by "classification". Since the introduction of the revised criteria, several studies ${ }^{3-5}$ have evaluated them, a few only in samples of patients with early disease. ${ }^{67}$ No study has investigated a cohort of patients including a sufficiant number of unclassified arthritis, reflecting the normal clinical situation in early diagnosis of arthritis. The incidence of both reactive arthritis ( $\mathrm{ReA})$ and undifferentiated arthritis (UA) in adults below the age of 60 is at least of the same magnitude as RA. ${ }^{89}$ Further- more, UA and other arthritides were seen more frequently than RA in early arthritis clinics. ${ }^{8} 10$ In addition it is crucial to differentiate RA as early as possible from the often benign and self limited forms of UA, as there is a need for early treatment of RA. ${ }^{11}$

In this analysis our objective was to evaluate the diagnostic performance of the 1987 ACR classification criteria for RA and the criteria of the French Society of Rheumatology (FSR) for $\mathrm{ReA}^{12}$ in a consecutive sample of patients with early arthritis as published previously. ${ }^{10}$

\section{Methods}

As published elsewhere in more detail ${ }^{10} 320$ patients older than 15 years with a duration of rheumatic symptoms of less than one year were prospectively examined. All patients were referred to the early arthritis outpatient clinic in the tertiary university referral centre by general practitioners and rheumatologists who were specifically informed about this institution. Patients had a standardised interview and rheumatological examination. Besides routine blood and serum parameters, immunological investigations (CRP, IgG, IgA, IgM, C3, C4, RF, ANA, DNA, HLA B-27) and a microbiological programme was done to search for infectious agents, such as Chlamydia trachomatis, Yersinia enterocolitica and pseudotuberculosis, Borrelia burgdorferi, and Campylobacter jejuni. Virological studies were done including hepatitis A and B. Patients had chest radiography and hand and feet radiography if joints of these areas were involved.

Diagnoses were expert diagnoses made by one of us (HZ) and were not based on classification criteria. The classic format of the 1987 ACR criteria ${ }^{2}$ for RA as well as the FSR criteria for $\mathrm{ReA}^{12}$ were applied retrospectively to all patients, regardless of the primary diagnosis. For diagnosis of ReA three criteria were required instead of four criteria as proposed by Amor, as this increased sensitivity. ${ }^{13}$ Sensitivity,

Table 1 Frequency of expert diagnoses of early inflammatory rheumatic diseases

\begin{tabular}{lcr}
\hline Diagnosis & Number & $\%$ \\
\hline Undifferentiated arthritis & 117 & 54 \\
Rheumatoid arthritis & 39 & 19 \\
Reactive arthritis & 24 & 11 \\
Polymyalgia rheumatica & 11 & 5 \\
Ankylosing spondylitis & 10 & 5 \\
Psoriatic arthritis & 7 & 3 \\
Sarcoidosis & 3 & 1 \\
Sacroiliitis with peripheral arthritis & 3 & 1 \\
Systemic lupus erythematosus & 3 & 1 \\
Total & 217 & 100 \\
\hline
\end{tabular}


Table 2 Number of patients (percentages) fulfilling the 1958 and the 1987 revised ACR criteria for rheumatoid arthritis and the FSR criteria for the diagnosis of reactive arthritis in the different diagnostic categories

\begin{tabular}{|c|c|c|c|c|}
\hline \multirow[b]{2}{*}{ Criteria sets } & \multicolumn{3}{|c|}{ Expert diagnoses } & \multirow{2}{*}{$\begin{array}{l}\text { Other } \\
\text { diagnoses } \\
(n=37)\end{array}$} \\
\hline & $\begin{array}{l}U A \\
(n=117)\end{array}$ & $\begin{array}{l}R A \\
(n=39)\end{array}$ & $\begin{array}{l}\operatorname{Re} A \\
(n=24)\end{array}$ & \\
\hline 1958 ARA criteria ( $\geqslant 5$ positive) & $23(20)$ & $39(100)$ & $4(17)$ & $3(8)$ \\
\hline 1987 ACR criteria ( $\geqslant 4$ positive) & $15(13)$ & $35(90)$ & $0(0)$ & $2(5)$ \\
\hline FSR criteria ( $\geqslant 3$ positive) & $14(12)$ & $0(0)$ & $19(79)$ & $1(3)$ \\
\hline
\end{tabular}

specificity, positive and negative predictive value, and positive and negative likelihood ratios were determined.

\section{Results}

During the study period of two years a total of 320 patients were referred of whom 217 had inflammatory rheumatic disease. Of these 217 patients, $117(54 \%)$ were considered as having undifferentiated arthritis (UA), whereas 39 patients (19\%) had RA, and 24 patients $(11 \%)$ had ReA (table 1).

Application of the 1985 and retrospective application of the 1987 revised ACR criteria for RA to all patients with inflammatory rheumatic diseases shows, that the 1958 criteria have a higher sensitivity of $100 \%$ compared with $90 \%$ sensitivity of the 1987 revised criteria. In UA $20 \%$ of the patients fulfilled five or more of the 1958 criteria, in ReA $17 \%$, and in the other diagnostic categories $8 \%$. Patients with UA were only positive in $13 \%$ for four or more 1987 criteria, none were positive in the group with $\operatorname{ReA}$, but $5 \%$ of the patients with other inflammatory rheumatic diseases. Thus, the specificity of the 1987 revised ACR criteria for RA reached $90 \%$ in this cohort of patients with early synovitis compared with a specificity of $83 \%$ of the 1958 criteria (table 2). The positive predictive value for the 1958 criteria is 0.57 , the negative predictive value 1.0 .

Similarly, with the application of the FSR criteria for ReA to the total cohort of patients with early synovitis, the sensitivity was $80 \%$. Fouteen patients $(12 \%)$ with UA and one patient $(3 \%)$ with other inflammatory rheumatic diseases fulfilled three and more criteria for the diagnosis of ReA (table 2). Thus, specificity of three and more of the diagnostic criteria for ReA reaches $92 \%$ with a positive predictive value of 0.55 , a negative predictive value of 0.97

\section{Discussion}

The 1987 revised ACR criteria for the classification of RA had a good performance in the cohort in which they were initially tested. ${ }^{2}$ They have been compared with the 1958 criteria in several cohort studies. ${ }^{4-6}$ Arnett et al reported a sensitivity of $91 \%-94 \%$ and a specificity of $89 \%$ in patients with established, mostly advanced diseases. In the medical literature sensitivity and specificity have been reported varying between $66 \%$ and $95 \%$ for sensitivity and $74 \%-98 \%$ for specificity. ${ }^{35-7}$

In this study the application of the 1987 revised ACR criteria for classification of RA revealed for both sensitivity and specificity a value of $90 \%$. Thus, the criteria had a great accuracy identifying patients with RA in this cohort of patients with early arthritis in contrast with most other reports. ${ }^{3467}$ The subanalysis of the ACR subcommittee on patients with disease duration of less than one year showed an estimated sensitivity of only $81 \%$, which was lower than the $91 \%$ obtained for the total of patients. The difference in sensitivities may be the result of different patient groups and may be influenced by the fact, that many patients, previously diagnosed as RA, were classified as UA in our cohort.

Finally, these results are substantiated by following up a limited number (24\%) of patients with UA over a medium period of 26 (4-38) months as reported earlier. ${ }^{10}$ Only a few patients with active disease developed definite seronegative RA $(7 \%)$ or AS $(4 \%)$ during the follow up.

The negative predictive value of 0.98 for four or more fulfilled criteria is high. This means, that a high accuracy exists to exclude RA in this cohort, if less than four of the ACR criteria are positive. The positive predictive value of 0.67 means, that only about 7 of 10 patients with four or more ACR criteria can be diagnosed correctly as having RA. The positive predictive value for five or more of the 1958 criteria is higher with 0.77 , while the negative predictive value is similar.

Clinically silent infections are increasingly recognised as a cause of seronegative arthritis. ${ }^{16}$ Diagnostic criteria for ReA have been proposed by the FSR ${ }^{12}$ but have not been evaluated in cohorts with different inflammatory rheumatic diseases. We have retrospectively applicated the criteria for ReA to our cohort of patients and found a sensitivity of $80 \%$ and a specificity of $92 \%$ for three and more criteria. The positive predictive value with 0.55 is rather low, while the negative predictive value of 0.97 is high. Thus, the criteria for ReA show a limited performance in patients with early synovitis. As only serology and culture techniques were used in this study, frequency of ReA could be higher using modern techniques, such as polymerase chain reaction in synovial fluid and in synovial tissue. In future, more sensitive diagnostic criteria including intra-articular identification of bacteria should be developed to advance the definite diagnosis of ReA. Meanwhile, many of the seronegative oligoarthritides with possible infectious aetiology can only be classified as UA. ${ }^{17}{ }^{18}$

In conclusion, in view of the good performance and the high accuracy found in this study, the 1987 ACR criteria are useful for the diagnosis of RA in an early arthritis outpatient clinic, where patients with undefined arthritis are frequently seen. ${ }^{8}{ }^{10}$ It is important to be able to diagnose and treat RA very early and to differentiate RA from benign, often self limiting forms of UA to avoid overtreatment of these latter patients. ${ }^{11}{ }^{19}$ ReA represents a third group of patients with increasing relevance to early differential diagnosis in clinical practice. Although the FSR criteria for ReA may miss patients with asymptomatic triggering infections, their future use in patients with early synovitis can be a first step towards a 
criteria based diagnosis of this important group of patients, otherwise classified mainly according to unstandardised tests and local definitions.

We are grateful to Dr W Mau for reviewing the manuscript and for his critical comments.

1 Ropes MW, Bennett GA, Cobb S, Jacox R, Jessar RA. 1958 revision of diagnostic criteria for rheumatoid arthritis. Bull Rheum Dis 1958;9:175-6.

2 Arnett FC, Edworthy SM, Bloch DA, McShane DJ, Fries JF, Cooper NS, et al. The American Rheumatism Association 1987 revised criteria for the classification of rheumatoid arthritis. Arthritis Rheum 1988;31:315-24.

3 Moens HJB, van de Laar AFJ, van der Korst JK. Comparison of the sensitivity and specificity of the 1958 and 1987 criteria for rheumatoid arthritis. J Rheumatol 1992;19: 198-203.

4 Jacobsson LTH, Knowler WC, Pillemer S, Hanson RL, Pettitt DJ, McCance DR, et al. A cross-sectional and longitutitt DJ, McCance DR, et al. A cross-sectional and longitutoid arthritis (equivalent to the American College of toid arthritis (equivalent to the American College of Rheumatology 1958 criteria) and the American College of Rheumatology 1987 criteria for
Arthritis Rheum 1994;37:1479-86.

5 Levin RW, Park J, Ostrov B, Reginato A, Baker DG, Bomalaski JS, et al. Clinical assessment of the 1987 American College of Rheumatology criteria for rheumatoid arthritis. Scand J Rheumatol 1996;25:277-81.

6 Dugowson CE, Nelson JL, Koepsell TD. Evaluation of the 1987 revised criteria for rheumatoid arthritis in a cohort of newly diagnosed female patients. Arthritis Rheum 1990; 33:1042-6.

7 Kaarela K, Kauppi J, Lehtinen KES. The value of the ACR 1987 criteria in very early rheumatoid arthritis. Scand J Rheumatol 1995;24:279-81.
8 Wolfe F, Ross K, Hawley DJ, Roberts FK, Cathey MA. The prognosis of rheumatoid arthritis and undifferentiated poyarthritis syndrome in the clinic: a study of 1141 patients. J Rheumatol 1993;20:2005-9.

9 Kvien TK, Glennas A, Melby K. Prediction of diagnosis in acute and subacute oligoarthritis of unknown origin. $\mathrm{Br}$ Rheumatol 1996;35:359-63.

10 Hülsemann JL, Zeidler H. Undifferentiated arthritis in an early synovitis out-patient clinic: Clin Exp Rheumatol $1995 ; 13: 37-43$

11 Van der Horst-Bruinsma IE, Speyer I, Visser H, Breedveld FC, Hazes JMW. Diagnosis and course of early-onset arthritis: results of a special early arthritis clinic compared to routine patient care. Br J Rheumatol 1998;37:1084-8.

12 Amor B. Reiter's syndrome and reactive arthritis: Clin Rheumatol 1983;2:315-19.

13 Viswat M. Undifferenzierte Arthritiden und Spondylarthropathien. Erfahrungen aus einer Früherkennungssprechstunde. [Medical thesis.] Düsseldorf: University of Düsseldorf, 1988.

14 Silman AJ. The role for epidemiology in rheumatology. Clin Exp Rheumatol 1992;10:105-8.

15 Fries JF, Hochberg MC, Metsger TA, Hunder GG Bombardier C. Criteria for rheumatic disease. Different types and different functions. Arthritis Rheum 1994;37: 454-62.

16 Weyand CM, Goronzy JJ. Clinically silent infections in patients with oligoarthritis: results of a prospective study. Ann Rheum Dis 1992;51:253-8.

17 Zeidler H. Undifferentiated arthritis and spondylartropathy as a major problem of diagnosis and classification. Scand J Rheumatol 1987;65 (suppl):54-62.

18 Sieper J, Braun J, Brandt J, Miksits K, Heesemann J, Laitko $\mathrm{S}$, et al. Pathogenetic role of Chlamydia, Yersinia and Borrelia in undifferentiated oligoarthritis. J Rheumatol 1992; 19:1236-42

19 Tunn EJ Bacon PA. Differentiating persistent from self-limiting symmetrical synovitis in an early arthritis clinic. Br J Rheumatol 1993;32:97-103. 